\title{
Gastric carbon dioxide concentration following bag and mask ventilation in children
}

\section{Lester AH Critchley, Jie Zhang. The Chinese University of Hong Kong.}

Chinese University

Department of Anaesthesia and Intensive Care, Prince of Wales Hospital, Hong Kong.

\section{Background and Goals of Study:}

Unrecognized placement of an endotracheal tube (ETT) in the oesophagus is a potentially life threatening complication of tracheal intubation. Correct ETT position is confirmed by presence of carbon dioxide $\left(\mathrm{CO}_{2}\right)$ in exhaled gas. Following bagmask ventilation in children a high and deceptive level of end tidal (ET) $\mathrm{CO}_{2}$ can be present in the expired gas following inadvertent oesophageal intubation. We sampled gastric gas $\mathrm{CO}_{2}$ levels in anaesthetized children following bag-mask ventilation at induction to demonstrate this possibility.

\section{Materials and Methods:}

Twenty-one children were recruited. Anaesthesia was induced and child bag-mask ventilated using a Jackson-Rees T-piece circuit. Intravenous lines were inserted and the trachea intubated. The airway management provider was usually a resident supervised by senior. After securing the airway mechanical ventilation was started and a size 10 suction catheter was passed into the stomach via mouth. The $\mathrm{ETCO}_{2}$ monitoring line was disconnected and attached to the open end of the suction catheter. Gastric gas was sampled for 10-seconds and displayed. The level of gastric $\mathrm{CO}_{2}$ was measured from the $\mathrm{ETCO}_{2}$ trace (Fig.).

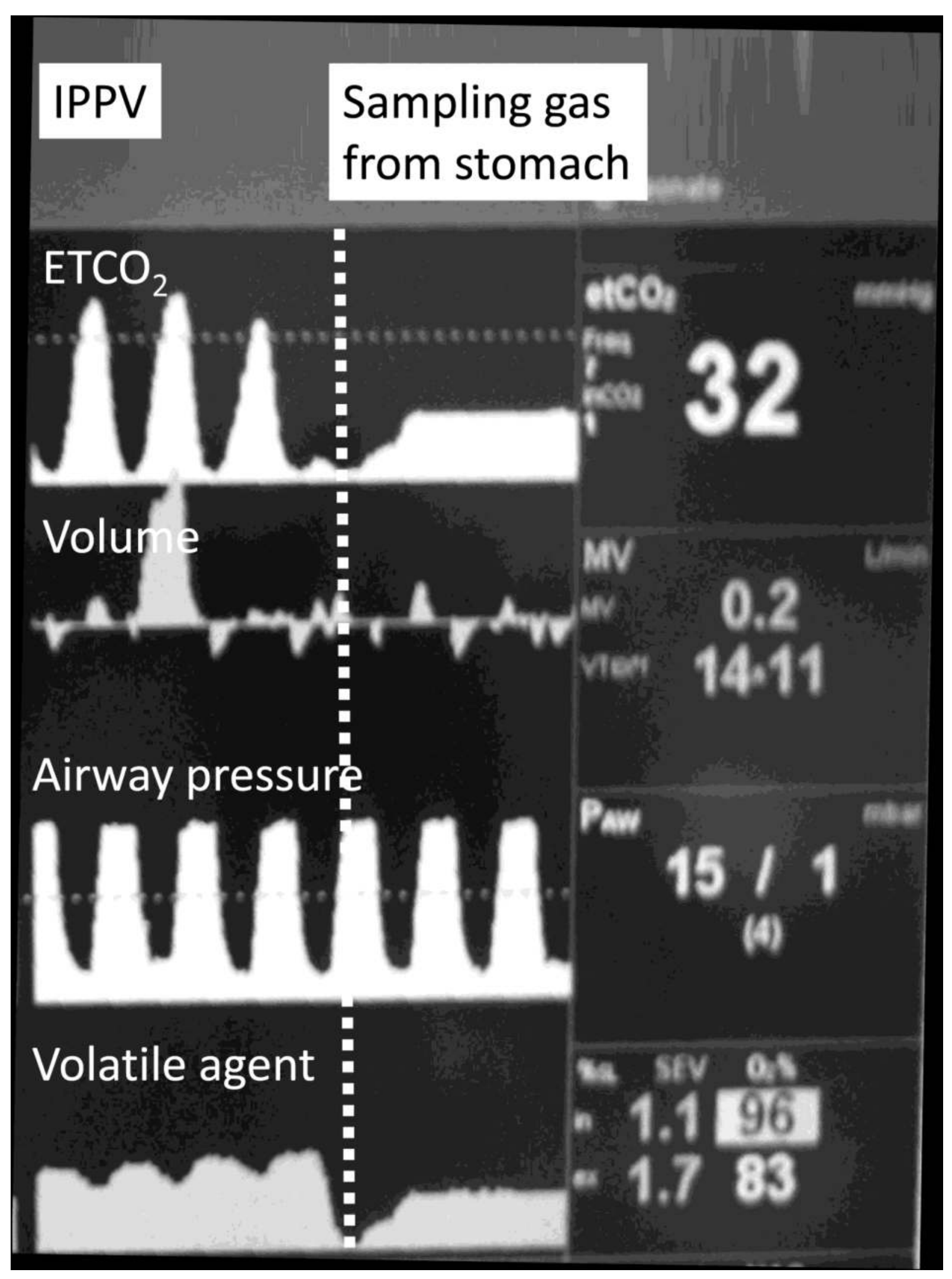

\section{Results and Discussion:}

Median (range) age was $14(0-60)$ months, and weight was $9(3-25) \mathrm{kg}$. Children were bag-mask ventilated for 4(1-20) minutes with fresh gas flow rate of 6(3-18) $\mathrm{L} / \mathrm{min}$. Gastric gas could be sampled in all cases. The mean (range) level of gastric $\mathrm{CO}_{2}$ detected was 29 (1252) $\mathrm{mmHg}$. The child with highest level of gastric $\mathrm{CO}_{2}$ was bag-mask ventilated for 10 minutes.

Significant levels of $\mathrm{CO}_{2}$ are found in the stomach following bag- mask ventilation in young children. These levels are sufficiently high to cause confusion when using the $\mathrm{ETCO}_{2}$ trace as evidence of successful tracheal intubation. Holding a face mask and ventilating using a Jackson-Rees circuit can result alveolar gas rich in $\mathrm{CO}_{2}$ entering the stomach. Presence of volatile agent in the gas was consistence with an alveolar origin (Fig.). The longer and more difficult the period of manual ventilation the greater the amount that accumulates.

Table showing data from those cases with the highest gastric $\mathrm{CO}_{2}$ levels. (" difficult ventilation / gastric distention)

\begin{tabular}{|l|c|c|c|c|c|}
\hline Type of Surgery & $\begin{array}{c}\text { Age } \\
\text { (months) }\end{array}$ & $\begin{array}{c}\text { Weight } \\
(\mathbf{k g})\end{array}$ & $\begin{array}{c}\text { Gastric } \mathbf{C O}_{\mathbf{2}} \\
(\mathbf{m m H g})\end{array}$ & $\begin{array}{c}\text { Duration } \\
\text { bag-mask }\end{array}$ & $\begin{array}{c}\text { Method of } \\
\text { induction }\end{array}$ \\
\hline Supracondylar \# & 48 & 17 & 30 & $5 \mathrm{~min}$ & $\mathrm{IV}^{*}$ \\
\hline Lap. Hernia repair & 4 & 8 & 33 & $8 \mathrm{~min}$ & gas \\
\hline Umbilical Cyst & 36 & 16 & 34 & $7 \mathrm{~min}$ & gas $^{*}$ \\
\hline Rectal pull throw & 32 & 12 & 35 & $6 \mathrm{~min}$ & gas \\
\hline Lap. Hernia repair & 17 & 9 & 36 & $7 \mathrm{~min}$ & gas $^{*}$ \\
\hline Hypospadius & 15 & 12 & 44 & $4 \mathrm{~min}$ & $\mathrm{IV}$ \\
\hline Duplex kidney & 31 & 16 & 45 & $5 \mathrm{~min}$ & $\mathrm{IV}$ \\
\hline Digit transplant & 36 & 15 & 50 & $14 \mathrm{~min}$ & gas \\
\hline Cystoscopy & 4 & 7 & 52 & $15 \mathrm{~min}$ & gas $^{*}$ \\
\hline
\end{tabular}

\section{Conclusion:}

Significant amounts of $\mathrm{CO}_{2}$ often in excess of 30 $\mathrm{mmHg}$ may be initially detected following oesophageal intubation in children as a result of bag-mask ventilation. Therefore presence of $\mathrm{CO}_{2}$ to confirm correct ETT position is not totally reliable in children and the $\mathrm{ETCO}_{2}$ trace should be confirmed over several ventilator cycles. 